\title{
Marathon vs sprint racers: an adaptation of sperm characteristics to the reproductive strategy of Pacific oyster, turbot and seabass
}

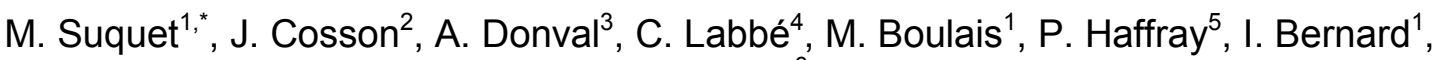 \\ C. Fauvel ${ }^{6}$
}

${ }^{1}$ Ifremer, UMR 100, Station Expérimentale d'Argenton, Argenton, France

${ }^{2}$ Faculty of Fisheries and Protection of waters, University of South Bohemia in Ceske Budejovice, South Bohemian Research Center of Aquaculture and Biodiversity of Hydrocenoses, Vodnany, Czech Republic

${ }^{3}$ IUEM, Lemar, UMR 100, Technopole Brest Iroise, Plouzané, France

4 INRA, Rennes, France

${ }^{5}$ SYSAAF, LPGP, Rennes, France

${ }^{6}$ Ifremer, UMR 5119 Ecosym, Université Montpellier 2, Palavas, France

*: Corresponding author : Marc Suquet, email address : $\underline{\text { msuquet@ifremer.fr }}$

\begin{abstract}
:
This work assesses the present knowledge on Pacific oyster sperm biology in comparison to two marine fish species (turbot and seabass) whose sperm characteristics are well described. Sperm morphology mainly differs by the presence of an acrosome in Pacific oyster which is absent in both fish species. In turbot as in Pacific oyster, a sperm 'maturation process' along the genital tract is observed. Sperm motility is triggered by changes in osmolality for seabass and turbot and in $\mathrm{pH}$ for Pacific oyster. However, complementary factors are involved to maintain sperm immotile in the genital tract. Sperm movement duration is very long in Pacific oyster (20-24 h), compared to turbot (3-5 min) and seabass (40-50 s). A high capacity of ATP regeneration is observed in Pacific oyster sperm, sustained by the limited changes in its morphology observed at the end of the swimming phase. Then, the total distance covered by spermatozoa is very different among the studied species (seabass: $2 \mathrm{~mm}$, turbot: $12 \mathrm{~mm}$, Pacific oyster: $1 \mathrm{~m}$ ). Considering the main characteristics of sperm movement, the three studied species can be separated in two groups: the sprint racer group (seabass: high velocity and short distance covered) and the marathonian racer one (Pacific oyster: low velocity but covering long distances). To an intermediate extent, turbot sperm belongs to the sprint racer group. Then, the two different sperm movement strategies observed in the three species, are compensated by the behaviour of the breeders.
\end{abstract}




\section{Introduction}

Pacific oyster (Crassostrea gigas) farming used to rely almost exclusively on spat collected from the wild. However, natural recruitment can vary considerably from one year to another. This explains the soaring role of hatcheries in Pacific oyster farming (Robert and Gérard, 1999). Yet, techniques used for Pacific oyster reproduction have changed very little since pioneer's works (Galstoff, 1930 and 1940).

The biology of Pacific oyster sperm remains little explored. Papers previously published in this species mainly deal with sperm morphology (Bozzo et al., 1993; Faure, 1996), sperm motility initiation (Devauchelle et al., 1994; Faure, 1996), the effects of different factors on sperm movement characteristics (Faure, 1996; Nice, 2005) and the changes in sperm features during the movement phase (Suquet et al, 2010). This limited knowledge on oyster sperm can be explained by i) the very high fecundity observed in both sexes (close to $50 \times 10^{6}$ oocytes per female, Helme and Bourne, 2004; $20 \times 10^{9}$ spermatozoa per male, Dong et al., 2005a), ii) the traditional rearing practices used for the reproduction of this species. Both factors allow mass production of Pacific oyster larvae regardless of gamete biology knowledge.

However, today aquaculture is improving the control of its production by using controlled crosses for selective breeding plans in order to improve disease resistance and growth rate, by creating special lines such as tetraploids in order to produce sterile offspring whose quality will not be altered during the reproductive season and by cryopreserving gametes in order to facilitate line preservation and diffusion. These techniques require the development of standardised procedures for which a good knowledge on gamete biology and a high control of their quality are required (Fauvel et al., 2010; Piferrer et al., 2009). Cryopreservation of Pacific oyster sperm is a representative example of such a requirement since large individual differences in sperm post thaw survival were reported (Dong et al., 2005b). As a consequence, the control of initial sperm quality becomes a major issue.

The aim of this paper is to compare Pacific oyster sperm characteristics with those of two marine fish species (turbot, Psetta maxima and seabass, Dicentrarchus labrax), which have been well described (Chauvaud et al., 1995; Cosson et al., 2008a and b; Dreanno, 1998; Fauvel et al., 1999).

\section{Sperm morphology}

The general morphology of spermatozoa is similar between the three studied species, all belonging to the primitive type as described by Franzen (1970) and presenting a rounded or conical head, a middle piece and a long flagellum consisting of a typical ' $9+2$ ' axoneme. They can also be termed aquasperm, used for species presenting external fertilization (Jamieson, 1991).

However, sperm morphology in the oyster mainly differs by the presence of an acrosome thereby giving an ovoid shape to the head (Faure, 1996) while turbot and seabass sperm have, as typical teleosts, no acrosome (Dreanno, 1998). The acrosome allows the spermatozoon to penetrate the 
egg enveloping layers during fertilization. In fish species lacking an acrosome, the micropyle provides a passage for sperm entry through egg layers towards the egg plasma membrane (Jamieson, 1991).

\section{Sperm 'maturation process' along the genital ducts}

In turbot, the percentage of motile spermatozoa collected from the testes is lower than that assessed for spermatozoa collected at the gonopore. Similarly, the flagellar beat frequency of Pacific oyster spermatozoa collected in testes is lower than that of spermatozoa released at the gonopore, after intragonadal serotonin injection (Fig. 1). These observations suggest a sperm 'maturation process' along the genital tract in these species.

Sperm 'maturation process' can be in vitro simulated in Pacific oyster: addition of $10 \mathrm{mM}$ caffeine to seawater increased the flagellar beat frequency of intratesticular spermatozoa (Fig. 2). The flagellar beat frequency of these in vitro matured spermatozoa is similar to that observed for spermatozoa released at the gonopore, after intragonadal serotonin injection (40-50 Hz, Fig. 1). The addition of caffeine also enhanced the percentage of motility of tetraploid Pacific oyster sperm collected in testes (Dong et al., 2002). Caffeine but also theophylline, act as phosphodiesterase inhibitors, thus raising intracellular cAMP (Weiss, 1975). This stimulates protein phosphorylation which triggers sperm movement (Tash and Means, 1983). As a consequence, caffeine must be added in solutions designed to activate intratesticular Pacific oyster sperm.

\section{Sperm activation}

Sugar solutions, deprived of ions, are used to demonstrate that osmolality is a key factor for sperm activation. A synchronous activation of $100 \%$ turbot spermatozoa was observed in the range of 320 to $1000 \mathrm{mosmol}$ glucose solutions (Chauvaud et al., 1995). Hypertonicity also triggers the motility of seabass spermatozoa (Cosson et al., 2008a).

In Pacific oyster, the osmotic pressure of the seminal fluid is close to that of seawater (1020 mosm $~^{-1}$; Severe, unpublished result), suggesting this parameter is not involved in the maintenance of sperm immotility in the genital tract. In this species, changes in $\mathrm{pH}$ of swimming solutions trigger sperm motility, $100 \%$ motile spermatozoa being observed from $\mathrm{pH} 8.0$ to 9.0 (Faure, 1996). The percentage of motile spermatozoa collected from tetraploid Pacific oysters was higher than $90 \%$ for values of $\mathrm{pH}$ ranging from 8.0 to 11.5 (Dong et al., 2002). However, these papers assessing the effect of $\mathrm{pH}$ on the movement of Pacific oyster sperm, use only intratesticular sperm. As a consequence, it remains difficult to separate the respective contribution of sperm 'maturation process' and of sperm activation when measuring the effect of $\mathrm{pH}$ on Pacific oyster motility. Complementary experiments must be carried out using 'mature' spermatozoa, collected at the gonopore after serotonine injection.

Both values of osmotic pressure, assessed in the seminal fluid of turbot (317 \pm 2 mosm l$^{-1}$; Dreanno, 1998) and of $\mathrm{pH}$, measured in the seminal fluid of Pacific oyster (6.4 \pm 0.1 ; Faure, 1996) do not totally prevent sperm motility in the genital tract of these species, suggesting that complementary 
inhibitory factors are involved. The inhibitory effect of $\mathrm{CO}_{2}$ on the movement of turbot sperm has been demonstrated (Dreanno, 1998). The high sperm concentration in the semen contributes to prevent sperm motility by the generation of $\mathrm{CO}_{2}$ in milt.

\section{Sperm characteristics at the beginning of the movement phase}

Intracellular ATP content of immotile spermatozoa is low in oyster, compared to the values observed in seabass and turbot (Fig. 3a).

Just after sperm activation, the Straight Line Velocity (VSL) is higher in the studied fish species, compared to that recorded in Pacific oyster (Fig. 3b). At the beginning of sperm swimming phase, the flagellar beat frequency of the flagellum is also higher in both fish species (seabass: $58 \mathrm{~Hz}$, turbot: 55 Hz; Dreanno, 1998) compared to Pacific oyster (38 Hz; Faure, 1996).

\section{Changes in sperm characteristics during the motility phase}

The movement duration of seabass (40 to $50 \mathrm{~s}$ ) and turbot sperm ( 3 to 5 min) is very short (Dreanno, 1998), compared to values observed for Pacific oyster sperm (20 to 24h; Suquet et al., 2010).

Initial ATP content of seabass sperm drops to $25 \%$ of its initial value, 10 s after sperm activation (Dreanno et al., 1999a). This suggests a very low capacity of ATP regeneration during sperm movement in this species, mitochondrial oxidative phosphorylation remaining inefficient to compensate ATP hydrolysis. This low mitochondrial activity during sperm movement phase could be explained by the drastic changes of sperm morphology, observed 40s post activation: mitochondria are shrunk and intracristae spaces are enlarged (Dreanno et al., 1999a). In contrast, ATP content of Pacific oyster sperm decreases only to $94 \%$ of its initial value after a $24 \mathrm{~h}$ movement, suggesting a high ATP metabolism compensating for its hydrolysis by dynein motors and sustaining a long duration of sperm movement in this species. This high capacity of energy restoration during the swimming phase is sustained by the limited changes of sperm morphology mainly observed in the shape and structure of mitochondria after a $24 \mathrm{~h}$ movement period (Suquet et al., 2010).

Turbot presents an intermediate case: the supply of energy required for sperm motility is partly provided by mitochondrial activity of spermatozoa since $54 \%$ of the initial ATP content was still measured 10 s post activation (Dreanno et al., 1999b). Following a first movement phase, turbot spermatozoa transitorily $(30 \mathrm{mn})$ retransferred into a non activating medium for energy restoration, can reinitiate a second swimming phase, suggesting that the structural modifications observed after the first movement period (shrinkage of mitochondria and vacuoles observed in the midpiece), remain limited or are reversed. However, the structural modifications of mitochondria observed after the first swimming period could explain the partial restoration of ATP level (58\% of the initial content) and sperm motility ( $55 \%$ of the initial percentage of motile spermatozoa) assessed at the beginning of the second swimming phase (Dreanno et al., 1999b). The 
capacity of Pacific oyster sperm to perform a second swimming phase must be investigated.

\section{Total distance covered by spermatozoa during the movement phase}

The swimming characteristics of sperm (velocity and movement duration) recorded in the three studied species result in highly different total distances covered by spermatozoa during their movement period: $2 \mathrm{~mm}$ for seabass, $12 \mathrm{~mm}$ for turbot (Dreanno et al., 1999a) and close to $1 \mathrm{~m}$ for Pacific oyster (Suquet et al., 2010).

\section{Sperm efficiency}

Sperm efficiency can be assessed by the minimum sperm to egg ratio allowing the highest fertilization rate. In Pacific oyster, sperm efficiency is very low (500; Song et al., 2009) compared to values observed in turbot (6 000; Suquet et al., 1995) and seabass (70 000; Fauvel et al., 1999). Sperm efficiency can be improved by chemotaxis as observed in Pacific oyster (Faure, 1996) but also in turbot (Dreanno, 1998). Sperm aggregation in Pacific and American (Crassostrea virginica) oysters was firstly reported by Galstoff (1964), observing the sperm attraction by egg and the changes of sperm movement characteristics in the vicinity of egg. The molecular mechanisms of sperm - egg interactions are suggested to be different in vertebrates and invertebrates (Morisawa, 2008).

\section{Discussion}

Sperm 'maturation process' was firstly described in mammalian spermatozoa which acquire their movement potential during transit through the epididymis (Tournade, 1913). According to observations reported in Pacific oyster, seabass and turbot, this phenomenon was also reported in many aquatic species including scallop, Pecten maximus (Faure et al., 1994) and rainbow trout, Oncorhynchuss mykiss (Morisawa and Morisawa, 1990), showing that, although most aquatic species do not bear complex organs such as epididymis, the acquisition of a potential for sperm motility still operates at some level within the genital tract.

The general model based on the osmolality control of marine fish sperm motility is well established (Cosson et al., 2008a). The effect of $\mathrm{pH}$ on Pacific oyster sperm activation was also reported in sea urchin, Strongylocentrotus purpuratus: an increase in the intracellular $\mathrm{pH}$, modified by changes in external $\mathrm{pH}$, triggers sperm motility in this species (Christen et al., 1982). The motility of black-lip pearl oyster, Pinctada margaritifera, occurs when spermatozoa are transferred to alkaline seawater which $\mathrm{pH}$ ranges from 9.0 to 10.5 (Demoy-Schneider et al., 2012). Complementary factors were suggested : the inhibitory effect of $\mathrm{CO}_{2}$ on sperm motility was reported as early as 1918 by Cohn, working in sea urchin (Arbacia punctulata) but also in several flatfish species (Inaba et al., 2003).

The amount of ATP assessed in immotile turbot and seabass spermatozoa is similar to that measured in different fish species (from 18 to $233 \mathrm{nMole}$ 
$10^{-9}$ spermatozoa; Ingermann, 2008). ATP concentrations have been little reported in invertebrates: from 3.9 to 6.2 nMole $10^{-9}$ spermatozoa in sea urchins (Arbacia lixula and Paracentrotus lividus; Mita et al., 1994). But, intracellular ATP content higher than that measured in Pacific oyster was assessed in black-lip pearl oyster, ranging from 251 to 1977 nMole $10^{-9}$ spermatozoa (Demoy-Schneider et al., 2012). The very low capacity of ATP regeneration observed during seabass sperm movement was also described in rainbow trout (Christen et al., 1987).

The movement duration of marine fish sperm is generally short, ranging from 40s in seabass to 20 min in congers (Cosson et al., 2008b). On the other hand, sperm movement duration is longer in the few invertebrate species studied up to now: $4 \mathrm{~h}$ in scallop (Faure, 1996), 180h in American oyster (Rose and Heath, 1978). However, a short movement duration was observed in black-lip pearl oyster: 10 minutes (Demoy-Schneider et al., 2012).

The VSL values reported in the present work in the three studied species are similar to those reported in the literature for Pacific oyster $\left(40 \mu \mathrm{m} \mathrm{s}^{-1}\right.$; Jeong and Cho, 2005) and seabass (100 $\mathrm{m} \mathrm{s}^{-1}$; Abascal et al., 2007). Sperm VSL recorded in fish ranged from 20 in European eel (Anguilla anguilla; Asturiano et al., 2005) to $200 \mu \mathrm{m} \mathrm{s}^{-1}$ in Atlantic salmon (Salmo salar, Dziewulska et al., 2010). A high value of VSL $\left(220 \mu \mathrm{m} \mathrm{s}^{-1}\right)$ was observed in black-lip pearl oyster (Demoy-Schneider et al., 2012).

A brief summary of the main characteristics recorded during sperm movement (Table 1) suggests that the three studied species can be separated in two groups: i) the sprint racers, represented by seabass which sperm presents a high initial velocity, a short movement duration and a low total distance covered during the swimming phase. To an intermediate extent, turbot sperm also belongs to this group, the spermatozoa of which stop swimming after 10 minutes, ii) the marathonian racers represented by Pacific oyster which sperm presents a low velocity, a long movement duration and a high total distance covered. The low sperm to egg ratio required for Pacific oyster fertilization suggests a higher sperm efficiency in the marathonian group, compared to that assessed in the sprint racer one.

Sperm movement strategy is complementary to that observed for the breeders of the studied species. The success of fertilization requires the synchronization of male and female gamete release and is promoted by the proximity of individuals of both sexes. This was observed in turbot and seabass, where, in both species, spawning determinism is controlled by a mating behaviour. Isolated seabass females do not release their eggs while heterosexual or only female couples spontaneously spawn. When ready to spawn, the females approach the males face to face and then escape, inducing the chase resulting in a fast swimming behaviour of both sexes. Then, ova and spermatozoa are released simultaneously, insuring the proximity of gametes during fertilization.

As a compensation of the absence of mating due to the sedentary life of breeders, a three step strategy has been developed in Pacific oyster: i) The proximity of individual breeders: it is increased by the formation of oyster beds. Coastal areas were colonized because of Pacific oyster ability to adapt to a wide range of environmental conditions. The high population density of oyster beds is a key component of fertilization success (Serrao and Havenhand, 2009), ii) The timing of gamete release: the fertilization of Pacific oyster oocytes is promoted since spawns are mainly observed 
during the slack tide, when water currents are limited (Bernard, 2011). iii) The low capacity of oocyte self activation in seawater: the fertilization capacity of Pacific oyster oocytes is not affected after a $4 \mathrm{~h}$ period in seawater prior to fertilization (Song et al., 2009). These three arguments reflect an adaptative strategy of Pacific oyster to the sedentary life of breeders.

\section{Conclusion}

The present study emphazises the role of breeder behaviour and sperm movement in the reproduction strategy of three marine animal species. Regarding sperm behaviour, the three studied species can be classified either as sprint racers (seabass and turbot: high velocity and short distance covered during the motility phase) or as marathon runners (Pacific oyster: low velocity but covering long distances). Pacific oyster spermatozoa may be considered as having developed a compensative strategy in the absence of breeding mates in contrast to the reproductive strategy in fish.

\section{Acknowledgment}

The present study was financially supported by UE contract Reproseed (FP7- KBBE-2009-3).

\section{References}

Abascal, F.J.; Cosson, J.; Fauvel, C., 2007. Characterization of sperm motility in seabass: the effect of heavy metals and physiochemical variables on sperm motility. J. Fish Biol. 70, 509-522.

Asturiano, J.F.; Perez, L.; Garzon, D.; Penaranda, D.S.; Marco-Jimenez, F.; Martinez-Llorens, S.; Toma, A.; Jover, M., 2005: Effect of different methods for the induction of spermiation on semen quality in European eel. Aquacult. Res. 36, 1480-1487.

Bernard, I., 2011: Ecologie de la reproduction de l'huître creuse, Crassostreagigas, sur les côtes atlantiques françaises. Vers une explication de la variabilité du captage. PhD Thesis, Univ. La Rochelle, France, 195pp.

Bozzo, M.G.; Ribes, E.; Sagrista, E.; Poquet, M.; Durfort, M., 1993 : Fine structure of the spermatozoa of Crassostrea gigas (Mollusca, Bivalvia). Mol. Reprod. Dev. 34, 206-211.

Chauvaud, L.; Cosson, J.; Suquet, M.; Billard, M., 1995 : Sperm motility in turbot, Scophthalmus maximus: initiation of movement and changes with time of swimming characteristics. Env. Biol. Fish. 43, 341-349.

Cohn, E.J., 1918: Studies on the physiology of spermatozoa. Biol. Bull. 34, 167-218.

Cosson, J.; Groison A.L.; Suquet, M.; Fauvel, C.; Dreanno, C.; Billard, R., 2008a: Marine fish spermatozoa: racing ephemeral swimmers. Reproduction 136, 277-294.

Cosson, J.; Groison, A.L.; Suquet, M.; Fauvel, C.; Dreanno, C.; Billard, R., 2008b: Studying sperm motility in marine fish : an overview on the state of the art. J. Appl. Ichthyol. 24, 460-486. 
Christen, R.; Schackmann R.W.; Shapiro, B.M., 1982: Elevation of the intracellular $\mathrm{pH}$ activates respiration and motility of the sea urchin, Strongylocentrotus purpuratus. J. Biol. Chem. 25, 14881-14890.

Christen, R.; Gatti, J.L.; Billard, R., 1987: Trout sperm motility: the transient movement of trout sperm is related to changes in the concentration of ATP following the activation of the flagellar movement. Eur. J. Biochem. 166, 667-671.

Devauchelle, N.; Faure, C.; Girard, J.P., 1994 : The quality of the sperm of two bivalves: the oyster, Crassostrea gigas and the scallop, Pecten maximus. In: Measures for success, EAS Sp. Publ. 21, pp. 214-216.

Demoy-Schneider, M.; Levêque, A.; Schmitt, N.; Le Pennec, M.; Cosson, J., 2012. Motility activation and metabolism characteristics of spermatozoa of the black-lip-pearl oyster Pinctada margaritifera var: cumingii (Jameson, 1901). Theriogenology 77, 53-64.

Dong, Q.; Eudeline, B.; Allen, S.K.; Tiersch, T.R., 2002: Factors affecting sperm motility of tetraploid Pacific oysters. J. Shellfish Res. 21, 719723.

Dong, Q.; Eudeline, B.; Huang, C.; Tiersch, T., 2005a: Standardization of photometric measurement of sperm concentration from diploid and tetraploid Pacific oyster, Crassostrea gigas (Thunberg). Aquac. Res. 36, 86-93.

Dong, Q.; Huang, C.; Eudeline, B.; Tiersch, T.R., 2005b: Systematic factor optimization for cryopreservation of shipped sperm samples of diploid Pacific oysters, Crassostrea gigas. Cryobiology 51, 176-195.

Dreanno C., 1998 : Régulation de la mobilité des spermatozoïdes de turbot (Psetta maxima) et de bar (Dicentrarchus labrax). PhD Thesis, Fac Vie-santé, Univ. Rennes, France, 81pp.

Dreanno, C.; Cosson, J.; Suquet, M.; Cibert, C.; Fauvel, C.; Dorange, G.; Billard, R., 1999a: Effects of osmolality, morphology perturbations and intracellular nucleotide content during the movement of seabass (Dicentrarchus labrax) spermatozoa. J. Reprod. Fertil. 116, 113125.

Dreanno, C. ; Cosson, J. ; Suquet, M.; Seguin, F.; Dorange, G.; Billard, R., 1999b: Nucleotide content, oxydative phosphorylation, morphology and fertilizing capacity of turbot (Psetta maxima) spermatozoa during the motility period. Mol. Reprod. Develop. 53, 1-14.

Dziewulska, K.; Rzemieniecki, A.; Domagala, J., 2010: Motility and energetic status of Atlantic salmon (Salmo salar L.) sperm after refrigerated storage. J. Appl. Ichthyol. 26, 668-673.

Faure, C., 1996: Paramètres physiologiques de l'émission et de l'activation des gamètes mâles de deux mollusques bivalves, la coquille Saint Jacques Pecten maximus (L.) et l'huître creuse Crassostrea gigas (Thunberg). PhD Thesis, Fac D. Diderot, Univ. Paris VII, France, $255 \mathrm{pp}$.

Faure, C.; Devauchelle, N.; Girard, J.P., 1994 : Ionic factors affecting motility, respiration and fertilization rate of the sperm of the bivalve Pecten maximus (L.). J. Comp. Physiol. B 164, 444-450.

Fauvel, C.; Savoye, O.; Dreanno, C.; Cosson, J.; Suquet, M., 1999. Characteristics of sperm of captive seabass in relation to its fertilization potential. J. Fish Biol. 54, 356-369.

Fauvel, C.; Suquet, M.; Cosson, J., 2010: Evaluation of fish sperm quality. J. Appl. Ichthyol 26, 636-643.

Franzen, A., 1970: Phylogenetic aspects of the morphology of spermatozoa and spermiogenesis. In: Comparative spermatology. Ed.: B. Bacetti, Academic Press, New York, USA, pp 29-46. 
Galstoff, P.S., 1930: The role of chemical stimulation in the spawning reactions of Ostrea virginica and Ostrea gigas. Proc. Nat. Acad. Sci. 16, 555-559.

Galstoff, P.S., 1940: Physiology of reproduction of Ostrea virginica. III. Stimulation of spawning in the male oyster. Biol. Bull. 78,118-135.

Galstoff., 1964. The American oyster Crassostrea virginica Gmelin. Fish Bull. Fish Wild. Ser., Washington, USA, 64pp.

Helme, M.M.; Bourne, N., 2004 : Hatchery culture of bivalves : A practical manual. FAO Fisheries Technical Paper. FAO, Rome, pp 177, ISBN 92-5-105224-7.

Inaba, K.; Dreanno, C.; Cosson, J., 2003: Control of flatfish sperm motility by $\mathrm{CO}_{2}$ and carbonic anhydrase. Cell Motil. Cytoskel. 55, 174-187.

Ingermann, R.L., 2008: Energy metabolism and respiration in fish spermatozoa. In: Fish spermatology. Eds: Alavi S.H.M.; Cosson J.; Coward K.; Rafiee G., Alpha Science International Ltd, Oxford. pp. 241-266. ISBN 978-1-84265-369-2.

Jamieson, B.G.M., 1991 : Fish evolution and systematics : Evidence from spermatozoa. Cambridge University Press, Cambridge, UK, 319 pp., ISBN 0-521-41304-4.

Jeong, W.G.; Cho, S.M., 2005: The effects of polycyclic aromatic hydrocarbon exposure on the fertilization and larval development of the Pacific oyster, Crassostrea gigas. J. Shellfish Res. 24, 209-213.

Mita, M.; Fujiwara, A., De Santis, R.; Yasumasu, I. , 1994 : High-energy phosphate compounds in spermatozoa of the sea urchins Arbacia lixula and Paracentrotus lividus. Comp. Biochem. Physiol. A 109, 269-275.

Morisawa, M., 2008: Adaptation and strategy for fertilization in the sperm of teleosts fish. J. Appl. Ichthyol 24, 362-370.

Morisawa, M.; Morisawa, S., 1990: Acquisition and initiation of sperm motility. In: Control of sperm motility: Biological and clinical aspects. Ed.: Gagnon C., CRC Press, Boston, USA, pp. 137-150, ISBN: 0849368596.

Nice, H.E., 2005: Sperm motility in the Pacific oyster (Crassostrea gigas) is affected by nonylphenol. Mar. Pollut. Bull. 50, 1668-1674.

Piferrer, F.; Beaumont, A.; Falguière, J.C.; Flajshans, M.; Haffray, P.; Colombo, L., 2009: Polyploid fish and shellfish : Production, biology and applications to aquaculture for performance improvement and genetic containment. Aquaculture 293, 125-156.

Robert, R.; Gérard, A., 1999: Bivalve hatchery technology: The current situation for the Pacific oyster Crassostrea gigas and the scallop Pecten maximus. Aquat. Living Resour. 12, 121-130.

Rose, C.D.; Heath, E., 1978: Viability of American oyster, Crassostrea virginica, spermatozoa exposed to stress. Estuaries 1, 245-251.

Serrao, E.A.; Havenhand, J., 2009: Fertilization strategies. In: Marine hard bottom communities. Ed.: M. Wahl, Springer-Verlag, Berlin, Germany, pp 149-164.

Song, Y.P.; Suquet, M.; Quéau, I.; Lebrun, L., 2009 : Setting of a procedure for experimental fertilisation of Pacific oyster (Crassostrea gigas) oocytes. Aquaculture 287, 311-314.

Suquet, M.; Billard, R.; Cosson, J.; Normant, Y.; Fauvel, C., 1995. Artificial insemination in turbot (Scophthalmus maximus): determination of the optimal sperm to egg ratio and time of gamete contact. Aquaculture 133, 83-90.

Suquet, M.; Labbe, C.; Brizard, R.; Donval, A.; Le Coz, J.R.; Quere, C.; Haffray, P., 2010: Changes in motility, ATP content, morphology and fertilization capacity during the movement phase of tetraploid Pacific oyster (Crassostrea gigas) sperm. Theriogenol. 74, 111-117. 
Tash, J.S.; Means, A.R., 1983: Cyclic adenosine 3', 5' monophosphtae, calcium and protein phosphorylation in flagellar motility. Biol. Reprod. 28, 75-104.

Tournade, A., 1913 : Différence de motilité des spermatozoïdes prélevés dans les

différents segments de l'épididyme. C. R. Soc. Biol. 74, 738.

Weiss, B., 1975: Differential activation and inhibition of the multiple forms of cyclic nucleotide phosphodiestrease. Adv. Cycl. Nucl. Res. 5,195211.

\section{Tables}

Table 1. Main characteristics recorded during the movement phase of seabass, turbot and Pacific oyster sperm.

\begin{tabular}{cccc}
\hline Parameter & seabass & turbot & Pacific oyster \\
\hline Sperm velocity & high & high & low \\
ATP regeneration & low & intermediate & high \\
Changes in morphology & high & intermediate & low \\
Movement duration & low & low & high \\
Total distance covered & low & low & high \\
\hline
\end{tabular}

\section{Figures}

Figure 1. Effect of sperm sampling localization (testes or gonopore, at least 30 spermatozoa observed for each male) on the movement characteristics (mean \pm SD) of turbot (6 males; Dreanno, 1998) and Pacific oyster sperm (3 males). Released Pacific oyster sperm were obtained after serotonin injection (100 $\mu \mathrm{l}$ of a $10 \mathrm{mM}$ solution; different letters refer to significantly different results as assessed by ANOVA and Tukey a posteriori test).
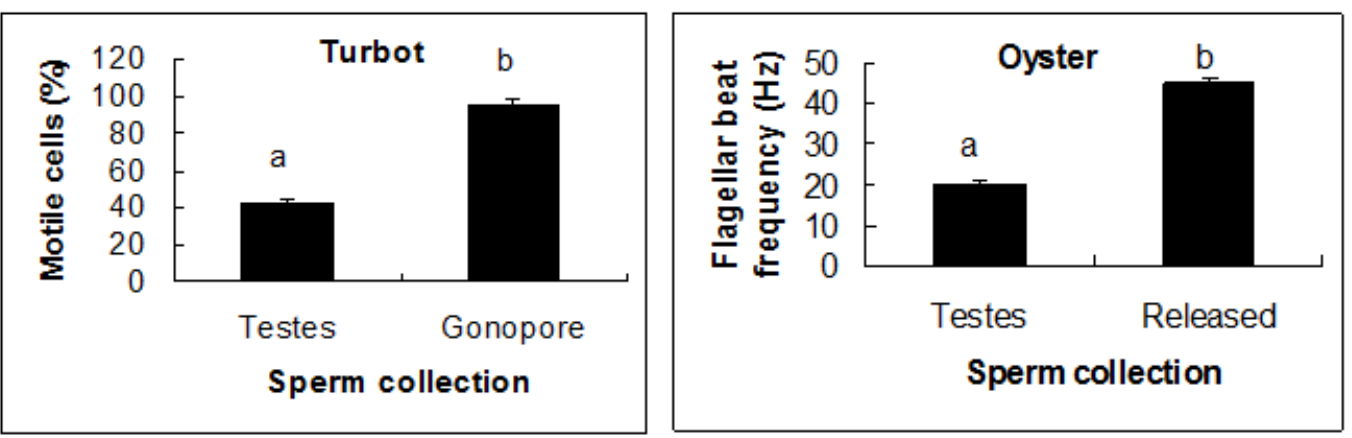
Figure 2. Effect of caffeine on flagellar beat frequency (observed according to Cosson et al., 2008a and b; mean \pm SD) of intratesticular Pacific oyster sperm (2 males, at least 30 spermatozoa observed for each male, different letters refer to significantly different results as assessed by ANOVA and Tukey a posteriori test).

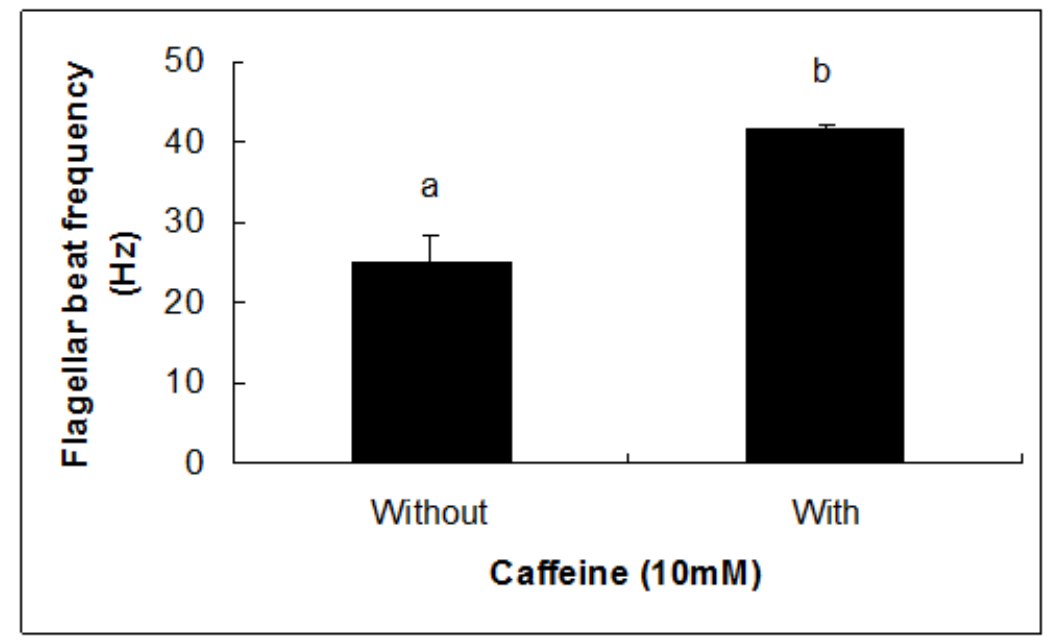

Figure 3. Intracellular sperm ATP content (a) and Straight Line velocity (b) assessed (mean \pm SD) at the beginning of the movement phase (ATP: 15 males for turbot and seabass-200 $\mu$ sperm samples, 3 males for Pacific oyster-500 $\mu$ sperm samples; VSL: 15 males for turbot and seabass, 3 males for Pacific oyster, at least 30 spermatozoa observed for each male; from Dreanno, 1998; Suquet et al., 2010; Cosson and Devauchelle, unpublished results).
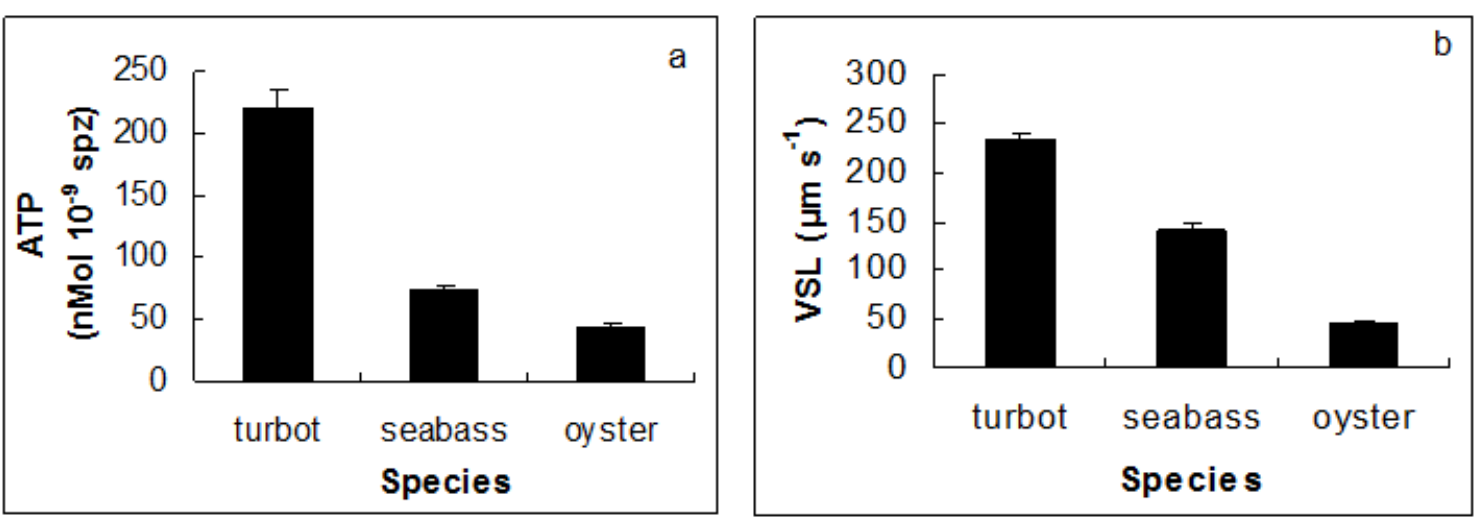